\title{
The recency effect: Implicit learning with explicit retrieval?
}

\author{
ALAN D. BADDELEY \\ MRC Applied Psychology Unit, Cambridge, England \\ and \\ GRAHAM HITCH \\ Lancaster University, Lancaster, England
}

\begin{abstract}
The recency effect in free recall features prominently in 1960s' theorizing about short-term memory, but has since been largely ignored. We argue that this stems from a preoccupation with the role of recency in the concept of primary memory and the neglect of its role in a broader working-memory framework. It is suggested that the recency effect reflects the application of an explicit retrieval strategy to the residue of implicit learning within a range of cognitive systems. When retrieved implicitly, the same residue is assumed to form the basis of priming effects. The various criteria for implicit learning described by Tulving and Schacter (1990) are successfully applied to the recency effect, and a retrieval process is outlined that can account for both long-and short-term recency effects. It is suggested that a framework combining recency, priming, and implicit learning provides a basis for understanding one of the most important features of cognition and memory, namely, that of maintaining orientation in time and place.
\end{abstract}

When subjects are presented with a list of words for immediate free recall, the last few words presented tend to be recalled very well, the phenomenon being known as the recency effect. It was a phenomenon of considerable interest and theoretical concern during the 1960s and features in most basic textbooks, but has in recent years been relatively neglected by both empirical researchers and by theorists. It has, in short, become rather unfashionable. We ourselves have tended to neglect the study of recency, concentrating instead on the more active features of the multicomponent working-memory model that has increasingly displaced the earlier concept of shortterm memory (Baddeley, 1992).

Although psychology is often accused of being excessively prone to changes of fashion, there are, of course, good reasons for ignoring particular topics. For example, a phenomenon might be sufficiently well understood that no further work is necessary. We would argue that this is not the case with recency. Alternatively, investigators may find that they are making little progress, and they very reasonably move to problems that may be more tractable. We would argue, on the contrary, that considerable progress has been made in understanding recency, although this tends not to be reflected in the standard textbook view. A third reason is that theoretical progress makes other areas seem more attractive. We believe this is the case with the phenomenon of recency, but we would like to argue that the time has come to attempt to relate

We are grateful to Robert Crowder and Richard Schweickert for their helpful comments on an earlier draft. Correspondence should be addressed to A. D. Baddeley, MRC Applied Psychology Unit, 15 Chaucer Road, Cambridge CB2 2EF, England. what we know about recency to some of the developments in other areas that have occurred since its heyday in the 1960s. More specifically, we wish to argue that the current interest in the concept of implicit and explicit memory is of direct relevance to understanding the recency effect and placing it within a broader context.

\section{Recency as Primary Memory}

Before going on to discuss the proposed reconceptualization of recency, it is necessary to rule out the simple 1960 s view that recency represents the contents of a primary memory store, a view proposed most vigorously by Glanzer (1972). This view argues for a short-term store of limited capacity, able to hold about three items, or chunks, of information, and able to retrieve this information relatively rapidly and with minimal cognitive demand. In the standard free-recall paradigm, the last few items are assumed to be in such a store and, hence, able to be readily recalled. However, if a word list is followed by some intervening activity such as counting, then the word list will be displaced from the primary memory store by the counting material, hence removing the recency effect (Glanzer \& Cunitz, 1966).

Evidence in favor of a short-term-storage view includes: (1) the demonstration by Glanzer and his colleagues that recency was uninfluenced by variables that have a major effect on earlier items in the list, such as rate of presentation and word frequency (Glanzer, 1972); (2) the demonstration that the recency effect is preserved in amnesic patients with defective long-term memory (Baddeley \& Warrington, 1970) and disrupted in patients with impaired short-term memory (Shallice \& Warrington, 1970); and (3) the demonstration by Rundus (1971) that subjects in- 
duced to rehearse out loud typically include the most recent items in their rehearsal and show a tendency for these to be recalled, regardless of the number of prior rehearsals. (A more detailed account of this literature is given by Baddeley, 1990, and Crowder, 1976.)

As Greene (1986b) has pointed out, the short-termmemory interpretation remains the view favored by many recent textbook writers, who tend to link the phenomenon to the modal model of memory (Atkinson \& Shiffrin, 1968), despite the presence of evidence that makes such an interpretation clearly questionable. The evidence will be described briefly, since it is discussed in more detail elsewhere (Baddeley \& Hitch, 1977; Greene, 1986b).

The first reason to doubt the primary-memory interpretation of recency comes from the demonstration of recency effects in long-term memory. These have been studied most extensively using the continuous-distractor technique, in which a list of words is presented with each word separated by some distractor activity such as backward counting, which then fills the interval between the final word and free recall (Bjork \& Whitten, 1974; Tzeng, 1973). Under these circumstances, a clear recency effect survives the filled interval, which under normal conditions would have been enough to wipe out recency. Other examples of long-term recency include the recall by subjects of anagram solutions, where each solution is followed by the demanding activity of solving the next anagram (Baddeley \& Hitch, 1977). Finally, recency effects can be shown to operate over a matter of weeks, as in the recall of rugby games (Baddeley \& Hitch, 1977) or parking locations (Pinto \& Baddeley, 1991). Subjects who park regularly in a given car park showed a marked recency effect when asked to recall their parking locations over the previous week, whereas subjects who park infrequently at that location were quite accurate in recalling their parking spot when tested 1 month later (Pinto \& Baddeley, 1991).

It is, of course, possible to argue that quite separate mechanisms are responsible for long- and short-term recency effects, although it then becomes problematic to explain why both are fitted by exactly the same function (Glenberg et al., 1980; Pinto \& Baddeley, 1991). Furthermore, Greene (1986a) has shown that at least two variables, word frequency and list length, have the same effect on both long- and short-term recency. A model that can explain the whole range of data would have advantages over a model that can only explain part of the data, particularly since attempts to demonstrate actively that the two types of recency are different have met with little success (see Greene, 1986b).

A second and related problem for the primary-memory interpretation of recency is presented by Watkins and Peynircioglu (1983), who demonstrated the existence of up to three simultaneous recency effects, each of which was comparable in magnitude to a recency effect under more conventional, single-stimulus conditions. They presented their subjects with lists of $\mathbf{4 5}$ items, selected from three highly distinctive categories, for example, riddles, sounds, and objects, presented in such a way that items from the three categories were interleaved. Hence, the $1 \mathrm{st}$, 4th, and 7 th items came from one category, the 2 nd, 5 th, and 8 th items from the second category, the 3rd, 6th, and 9th items from the third category, and so forth. After the 45th item, recall was cued with the category name; a marked recency effect was observed regardless of which of the three categories was cued. This is clearly very difficult to fit into an interpretation of recency that is based on a limitedcapacity primary memory other than by making the arbitrary post hoc assumption that the subject has a separate and parallel primary-memory system for each category.

The third problem for the primary-memory view of recency comes from the observation that concurrent activity that ought to occupy primary memory does not appear to interfere with recency. This is shown most strongly in two studies by Baddeley and Hitch (1977) in which free recall of lists of words presented visually in one study and auditorily in the second study was accompanied by a concurrent digit-span task presented in the other modality. Since both digit span and the recency effect are assumed in the short-term-memory view to depend upon the same limited-capacity primary memory, then the recency effect should be wiped out by this concurrent task. In fact, recency was quite unaffected, although performance on items earlier in the list was impaired.

It is not easy to see how a primary-memory interpretation of recency can account for this pattern of data, and we know of no attempt to do so. Historically, this was one of the major reasons for the demise of the concept of primary memory as it appeared in the multistore models of the 1960s (e.g., Atkinson \& Shiffrin, 1968; Waugh $\&$ Norman, 1965). The idea of a passive primary memory was replaced by more dynamic accounts of temporary information storage and information processing, such as the working-memory model (Baddeley, 1986; Baddeley $\&$ Hitch, 1974). However, recency itself became somewhat detached from this theoretical development, since the experimental data suggested it was not an aspect of working memory. Although recency has continued to attract interest, it has tended to become a specialized and somewhat isolated research topic.

In the next section, we describe work that suggests that a simple temporal or ordinal discrimination hypothesis fits the data from both long- and short-term recency extremely well. We then go on to describe an attempt to rehabilitate recency by arguing that it reflects registration in implicit memory by means of a process of priming.

\section{The Discrimination Hypothesis}

We argue that a simple temporal or ordinal discrimination hypothesis fits the data from both long- and shortterm recency extremely well. The essence of the hypothesis is perhaps best captured by the analogy proposed by Crowder (1976) of recall from a free-recall list as being rather like looking back at telegraph poles along a railway line. The nearest poles will be easy to discriminate, but as the poles become more distant it becomes progressively harder to tell one from the other. Similarly, if one 
moves further away from the nearest pole, then that pole will still be the most discriminable, and the immediately preceding one will be the next best, and so forth. Such a view has been quantified both by Glenberg and his colleagues and by Hitch and Rejman (Glenberg et al., 1980; Hitch, Rejman, \& Turner, 1980). By analogy with Weber's Law, the assumption is made that the discriminability of the memory trace of a particular item will be a joint function of the interval between that item and the next and the interval between that item and the point of recall, the so-called discrimination ratio.

However, although there is a fair amount of agreement on the nature of the function, there is considerably less agreement on the actual mechanism whereby the function is achieved. A number of authors have suggested the possibility that ordinal cues are involved (e.g., Baddeley \& Hitch, 1977; Sanders, 1975; Tulving, 1968). Others have emphasized temporal rather than ordinal distinctiveness (Bjork \& Whitten, 1974; Hitch et al., 1980), but on the whole, most accounts have left unspecified the manner in which the relevant cue of order or time is encoded and retrieved. There are, in fact, at least two models that attempt to specify a mechanism in slightly more detail, that of Glenberg et al. (1980) and that of Baddeley (1986).

Glenberg et al. (1980) dealt with the problem of time by assuming that it is represented by a continuously changing context; the context is assumed to change gradually so that the closer two events are in time, the more similar will be their contextual cue. Since the temporal context continues to run during a delay interval, the nearer a recall comes to the end of the list, the more similar the encoding and retrieval contexts will be, and the better the recall. A filled interval is assumed to disrupt and change the contextual situation, hence making the temporal retrieval cue ineffective. However, Glenberg et al. (1980) appeared to make no attempt to unconfound time and context, for example by deliberately changing the background context between learning and retrieval. They did, in fact, include a condition in which it is reasonable to assume that such a change occurs, since the level of difficulty of the concurrent task in a continuous distractor paradigm is changed between learning and retrieval (Glenberg et al., 1980). However, there does not appear to be any decrement in performance, as the contextual interpretation would predict.

It is also difficult to see how the contextual interpretation would handle the microstructure of the recency effect obtained in the Watkins and Peynircioglu (1983) study. Consider, for example, the critical comparison between the recency effect when only one category of task is involved and that in which three categories are interleaved. In the single-category case, the last item is substantially better recalled than the penultimate item, which in turn is better than the item before. According to the contextual interpretation, this is because the background context will have changed over this period of time, causing a disruption of the context and leading to poorer retrieval. Consider now the case where three different categories of task are interleaved, and compare the condition in which a subject attempts to recall the category presented third in order with that presented first. The last item of the third category will have been presented most recently, and the last item of the first category will have been presented at a point separated in time and, presumably, involving an even greater switch in context between learning and recall, and yet there is far less difference in probability of recall of this item than of the equivalently positioned item in the single-category list.

The continuous-temporal-context hypothesis would seem to have even more problems in coping with instances of very long-term recency, for which it has to assume a degree of precision of temporal encoding that appears to be inconsistent with what evidence is available for dating of events in long-term memory. For example, dates for public events appear typically to be derived from information concerning the organization of private, autobiographical events rather than via temporal information per se (Brown, Shevell, \& Rips, 1986).

A further difficulty is presented by a study by Pinto and Baddeley (1991) in which subjects who parked their cars at the Applied Psychology Unit a month earlier were asked by mail to remember and mark on a parking plan where they had parked. Subjects who had attended the unit only once in recent months recalled their parking locations as well after 1 month as they appeared to do after a week, or indeed on the same day. However, if they had been to the unit on two occasions, separated by a week, then recall a month later was considerably worse. These and other results from the same study fit the discrimination hypothesis very well, but it seems implausible to assume that there is a precise and continuous contextual cue that is still available 1 month later, when recall is tested by mail in a completely different context. Unless the hypothetical contextual change can be demonstrated much more convincingly, then it is hard to escape the view that the Glenberg et al. (1980) position merely relabels time as context and, as such, does not genuinely provide a mechanism whereby the phenomenon of recency can be explained.

The second proposed mechanism is Baddeley's (1986, chap. 7) suggestion that the recency effect is based on a phenomenon analogous to priming in that the memory representations of recent inputs are assumed to have increased levels of activation. This proposal has the drawback that it is speculative and relatively vague, but it does have the advantage that it is, in principle, able to be modeled. It is also timely in that activation levels are a central feature of current connectionist models of memory that are beginning to attempt to simulate recency as one of the more obvious and dramatic features of memory (e.g., Burgess, Shapiro, \& Moore, 1991; Parisi, 1986). In such models, learning typically involves changing the weights of connections throughout an associative network, and retrieval involves using these weights to recover the original learning. Recency emerges naturally because the weights tend to be altered by subsequent learning. 


\section{Recency as a Priming Effect}

Baddeley (1986) proposed that recency represents the application of a very basic retrieval mechanism to an isolable memory store or memory domain. The term priming refers in this instance to the process that is responsible for the greater availability of information about an item or event as a result of a previous presentation. Priming is typically inferred from the empirical phenomenon of the priming effect, in which performance on some (nonmemory) task is altered as a function of an earlier presentation of the material being processed. We use the term priming to refer to the underlying process, which we suggest may influence performance across a range of experimental paradigms, including both memory and nonmemory tasks. As Tulving and Schacter (1990) pointed out, priming effects occur across a wide range of systems, both perceptual and conceptual. Given the range of different systems, it is entirely plausible to assume that the mechanism may be somewhat different, in some cases based on a rapidly fading trace and in others possibly based on interference rather than temporal decay. What such situations have in common, however, is the greater availability of previously presented, and therefore of more recent, items.

How can the system take advantage of this? Clearly, in general, retrieval is not simply based on recency, otherwise the whole retrieval process would become locked into a loop whereby the most recent item is retrieved, thereby becoming even more recent and being even more likely to be retrieved. It seems probable that recency supports a special mechanism used as a supplement to more structured retrieval processes.

How might such a system work? An analogy is proposed whereby the items or events to be recalled are regarded as discriminable nodes within a network. These nodes will be treated as local representations of information, but it is to be understood that they could correspond to patterns of activation at some level within the network. Whether they are considered as nodes or distributed representations is essentially a matter of implementational choice. It is assumed that presentation and processing of an item results in the activation of its node and that recall of an item involves reactivating its node. The recency effect occurs because recently activated nodes are easy to reactivate. The analogy can be made with a bank of lights in which the filament of a given light becomes incandescent when a current is passed through. Presentation of a series of items corresponds to illuminating individual lights in turn. After the series has ended, the last few lights to have been illuminated will tend to be still warm, and one way of taking advantage of this is to flood the bank with a current that gradually increases in amplitude. The first lights to glow during this reactivation process will be those that were warmest, having more recently been illuminated.

An interesting feature of the analogy is that it leads naturally to some of the same predictions as the ratio rule. It is necessary only to assume that the probability of retrieving an item depends on the distinctiveness of its brightness from that of other potential retrieval targets. This, in turn, will be a function of the warmth of their filaments at the time of flooding. Provided the lamps cool at a gradually decreasing rate, and do so independently of one another, the distinctiveness of the warmth of a given lamp relative to the others will depend on time intervals in a way similar to the ratio rule. Thus, the more separated the initial lighting of individual lamps, the greater will be the difference in their warmth at the time of flooding. And since the lamps will cool toward a common baseline, their warmth will become more similar as the delay before flooding increases. We can, therefore, see by this analogy that a system involving discriminations among the activation levels of a set of memory representations is capable of producing recency, which conforms to the general pattern normally observed.

Another feature of the analogy is that if too high a current is passed through during flooding, then many lights will be illuminated, some recent, some distant, and some that were probably not illuminated before. A crucial variable is the domain within which the process of flooding can occur. Watkins and Peynircioglu (1983) managed to find sufficiently distinctive categories to allow them to set up three parallel recency effects, but this was not easy to achieve. Presenting subjects with items selected from three successive semantic categories will not produce three recency effects, but rather one (Rejman, 1979). This is not only a problem for the present theory, but it remains a phenomenon that has yet to be explained by any model. A more basic weakness of the flooding analogy, however, is that it essentially represents verbal speculation, and to become a genuine model it would need more detailed quantitative specification and, preferably, simulation.

In the meantime, how plausible is it to assume that the recency effect resembles priming in reflecting implicit learning, albeit accessed by an explicit retrieval process? We will attempt to answer this question by using the criteria applied by Tulving and Schacter (1990), who argued for perceptual priming as an implicit learning system.

\section{Recency as Implicit Learning}

Over the last decade, one of the most active research areas has been that concerned with the question of whether long-term memory can be regarded as comprising two separate systems, one based on explicit acquisition of information through a system often associated with episodic memory and the other concerned with one or more forms of learning that do not appear to depend on episodic memory and that have typically been termed implicit memory (Richardson-Klavehn \& Bjork, 1988). The distinction is reflected most clearly in studies of patients suffering from the classic amnesic syndrome, who, despite having no apparent capacity for recollecting new experiences, may nevertheless show an unimpaired capacity to show improvement with practice on a wide range of learning tasks, ranging from classical conditioning through perceptual priming and motor-skill learning to the acquisition of new problem-solving skills (Baddeley, 1982; Squire, 1982). 
Although the existence of a valid distinction between two or more types of long-term-memory tasks is widely accepted, there is much less agreement as to how such a distinction should best be conceptualized and as to what is the most appropriate terminology (Richardson-Klavehn \& Bjork, 1988). There is, however, general agreement that one class of implicit tasks that appears to be clearly separable from explicit learning is represented by priming effects. The case for this view was presented cogently by Tulving and Schacter (1990), and although it is questionable as to whether the range of perceptual priming phenomena they describe all reflect the operation of a single system, there would, we think, be general agreement that they all represent broadly comparable forms of implicit memory.

If, as suggested above, the recency effect is based on a priming mechanism, then one might reasonably expect that it also would meet the various criteria proposed by Tulving and Schacter (1990) for classifying learning as implicit, even though the recency effect is measured in quite a different way from the typical priming study. Whereas the perceptual priming effect is detected in a nonmemory task, as a change in responding to a stimulus as a function of a previous presentation, the recency effect in free recall is indicated by a change in the probability of recalling the stimulus (or event) in the absence of any specific external cue. The question of whether the characteristics of the recency effect resemble those of priming will be examined next; we will consider in turn the five criteria proposed by Tulving and Schacter.

1. Intact performance in amnesia. Amnesic patients typically show priming effects that are as marked as those found in control subjects (see, e.g., Graf, Squire, \& Mandler, 1984). In the case of recency, Baddeley and Warrington (1970) studied the free recall of lists of 10 words by a group of densely amnesic patients. When compared to controls, the amnesic patients showed grossly impaired performance on the earlier items in the list but revealed preserved recency. This has been replicated in studies with other amnesic patients (e.g., Wilson \& Baddeley, 1988) and with patients suffering memory deficit following closed-head injury (Brooks, 1975).

2. Developmental dissociation. Recognition memory in children increases with age, whereas priming can be as large in 3-year-olds as in college students (see, e.g., Parkin \& Streete, 1988). A similar pattern occurs for the recency effect. Using an immediate-free-recall task, Craik (1968) compared the performance of young subjects, averaging 22 years of age, and 65-year-olds. The older subjects performed more poorly on the earlier items in the list but showed equivalent recency to the younger subjects. Thurm and Glanzer (1971) carried out a broadly equivalent study using children; the younger children performed more poorly on the earlier items but showed as clear a recency effect as the older children.

3. Drug dissociations. Drugs such as alcohol and scopolamine impair explicit recall, while typically having no effect on priming (see, e.g., Parker, Schoenberg,
Schwartz, \& Tulving, 1983). Again, the recency effect shows a similar pattern. Mewaldt, Hinrichs, and Ghoneim (1983) studied the effect of the tranquilizer Valium on free-recall performance, observing the anticipated deficit following drug ingestion in recall of earlier items in a list but detecting no difference in the magnitude of the recency effect. An equivalent pattern has been observed for a range of other drugs that leave recency unchanged, including alcohol (Baddeley, 1981) and marijuana (Darley, Tinklenberg, Roth, Hollister, \& Atkinson, 1973).

4. Functional independence. This term was used by Tulving and Schacter (1990) to refer to the observation that variables that influence long-term episodic memory are found not to influence priming, and vice versa. Depth of processing (Craik \& Lockhart, 1972) is one of the most influential implicit-explicit dissociations, with priming failing to show the standard tendency for orthographic processing to lead to poorer recall than phonological processing, which in turn is less effective than semantic encoding (Jacoby \& Dallas, 1981).

As Glanzer (1972) pointed out, there are many examples of the functional independence of the recency component in free recall and performance on earlier items. Thus, earlier items tend to be influenced by variables such as number of repetitions and word frequency, which affect long-term learning, whereas the recency effect is typically resistant to such variables. Glanzer and Koppenaal (1977) studied the influence of depth of processing on the magnitude of the recency effect, observing that while performance on earlier items followed the pattern of deeper processing leading to better recall, the recency effect was uninfluenced by processing depth. Seamon and Murray (1976) obtained broadly similar results. Other evidence of insensitivity to the nature of coding came from a study by Craik and Levy (1970), in which they manipulated semantic similarity, again finding a dissociation between a clear effect on earlier items and the absence of an effect on recency.

5. Stochastic independence. This is the most controversial of Tulving and Schacter's (1990) criteria (Hintzman, 1991; Hintzman \& Hartry, 1990). For stochastic independence to occur, a given word presented at the end of a list should have a probability of being retrieved on the basis of recency that is independent of its probability of being recalled subsequently from long-term episodic memory. Such an assumption underlies many of the measures devised to estimate the primary-memory component of recency (see, e.g., Baddeley, 1970; Glanzer, 1972; Waugh \& Norman, 1965). Although we know of no studies that have explicitly set out to test this assumption at the level of the individual item, it is supported, at least qualitatively, by a study (Baddeley, 1968) concerned with the role of recency in multitrial free-recall learning. When recall probability was plotted as a function of serial position during presentation, words recalled for the first time showed a clear recency effect, whereas words correct on earlier trials showed no clear recency, although in both cases subjects tended to recall more recent items first. 
One might possibly argue that the occurrence of the negative recency effect argues against the assumption of stochastic independence. Negative recency is the observation that when immediate free recall of one or more lists is followed by a final free recall, the last one or two items tend to be particularly poorly remembered (Craik, 1970). Given that these are the items that are best remembered on immediate free recall, one might contend that this argues for a negative correlation, rather than stochastic independence. However, it appears to be the case that negative recency reflects the influence of immediate recall on subsequent recall, since it does not occur when immediate free recall is not required (see Greene, 1986a, for a discussion). The fact that immediate recall may influence subsequent delayed recall does, of course, make it very difficult to test for stochastic independence at the level of the individual word. Hence, if Hintzman (1991) is wrong, and stochastic independence is an important criterion of implicit learning, then we may have to be satisfied with the broad evidence of independence that is presented by the fact that serial position over the latter half of a free-recall list has a massive effect on immediate recall and, typically, no effect on delayed recall.

To recapitulate, Tulving and Schacter (1990) specify five criteria of implicit memory, each of which they apply successfully to the phenomenon of priming. When these are applied in turn to the recency effect, the evidence is consistent in suggesting that the recency effect meets all five criteria of implicit memory.

\section{Recency in Implicit Memory Tests}

We next consider the evidence that recency effects can be observed under implicit retrieval conditions. The most obvious example of this is the evidence that priming effects gradually dissipate as a function of the lag separating the rest from the priming presentation. The time course of this function can be very rapid (Kirsner \& Smith, 1974; Monsell, 1985), although long-lived priming effects that are resistant to forgetting can persist over periods as long as a week (Tulving, Schacter, \& Stark, 1982).

A somewhat different demonstration of recency in implicit memory comes from a series of experiments reported by McKenzie and Humphreys (1991). In a typical study, subjects performed a different classification task on each of two successively presented word lists under incidental learning instructions. After a variable delay, they then performed either an explicit test of memory or an implicit test. For example, subjects were presented with a part-word cue containing some of the letters of a word they had seen. In the explicit condition, subjects were asked to complete the part-word cue to form any of the words that they could remember having seen in the first list. In the implicit condition, they were asked simply to produce the first word that came to mind as a completion for the cue. The two lists were designed so that there was always one word on each that matched the cue, and thus the proportion of List 2 to List 1 responses could be used as an index of recency. McKenzie and Humphreys re- ported a higher proportion of List 2 responses at the shorter delay, and this was true on both the explicit and implicit tests. Subjects appeared to be obeying the two sets of instructions, since the proportion of extralist responses was much higher for the implicit group. McKenzie and Humphreys's results, therefore, argue convincingly that recency effects can occur under both explicit and implicit retrieval conditions.

If we go back to the analogy of a bank of lights, the implicit recency effect can be understood in terms of the gradual cooling of the lamps with increasing lag since their illumination. This in turn suggests the possibility that recency in implicit and explicit memory tests may be systematically related, since they both depend on activation levels but in slightly different ways. As we have seen, recency in tests of explicit memory appears to reflect the ease of discriminations based on differences among the activation levels of the various presented items. We would expect recency in implicit memory to be a function of differences between the activation levels of presented and nonpresented items. Such an interpretation leads to some clear predictions. For example, one would expect that the time scale over which recency is observed for a particular type of material would be similar in tests of explicit memory and in measures of priming effects.

Recency clearly satisfies Tulving and Schacter's (1990) criteria for classification as implicit memory. It may, therefore, seem somewhat paradoxical that recency is typically found under conditions where subjects are intentionally recollecting past experience. However, the apparent contradiction disappears if we assume that recency reflects the application of an explicit retrieval strategy to implicit learning. To examine this suggestion, we need to consider first whether there is evidence that recency is dependent on the application of a retrieval strategy.

The belief that recency involves a particular retrieval strategy was widely held by experimenters studying immediate free recall in the 1960 s and 1970 s who would typically attempt to maximize the size of the recency effect by instructing subjects to try to recall the last items first. If such instructions were not given, some subjects would typically take a few trials before they recalled in this way. One of the first studies to show the buildup of recency across trials was one using minimal pairedassociate learning (Murdock, 1963). The strategic basis of recency is clearly illustrated by Baddeley and Wilson's (1988) study of a frontal amnesic patient, R.J. Patients with frontal damage tend to perseverate, and having begun to retrieve the early words of a list first, R.J. showed a complete absence of recency. However, on the following day, he began with a strategy of recalling the most recent words, and he continued to do so, demonstrating a very clear recency effect.

Further evidence for the importance of output order comes from one of the studies reported by Baddeley and Hitch (1977) in which subjects were presented with a list of nonsense syllables under instructions for either intentional or incidental learning. Within each group, half the 
subjects were required to perform a supplementary writing task involving copying each item several times as it was presented. Recency was found for three of the four groups and was absent only for subjects who engaged in intentional learning without the supplementary task. In all three conditions that showed recency, there was a clear tendency for subjects to start recalling with the last items, whereas in the one condition that did not show recency, subjects tended to begin by recalling from the start of the list. These data argue strongly for an association between the recency effect and a retrieval strategy involving a lastin-first-out output order. The importance of output order is further confirmed by evidence that when subjects are instructed to start by retrieving items from the beginning, middle, or end of the list in immediate free recall, recency is only found when subjects retrieve the last items first (Dalezman, 1976).

There is, then, some very strong evidence that recency depends on the adoption of a retrieval strategy that involves recalling the last items first. However, most of the evidence concerns immediate recall, and it appears that output order may be less important in the case of longterm recency. For example, Whitten (1978) examined the effects of instructing subjects to begin recalling at the beginning, middle, or end of the list in the continuousdistractor task. He found that the long-term recency effect in this task was not dependent on recalling the last item first. This evidence obviously challenges the view that recency is always dependent on a particular way of ordering the retrieval process. However, the differential importance of output order in short- and long-term recency is consistent with the view that the retrieval process involves some form of internal discrimination. We saw earlier that support for this idea comes from the "ratio rule"' (Glenberg, Bradley, Kraus, \& Renzaglia, 1983; Glenberg et al., 1980; Hitch, 1985), which is such that the probability of recall reflects the Weber fraction expressing the interval separating events from one another as a proportion of the interval separating them from the present. Differences in output order will add to the second of these two intervals, leaving the first unaffected. Thus, a change in output order will have a large effect on the discrimination ratio in immediate free recall, since the interval between presentation and retrieval is relatively small. However, the same change in output order will have a much smaller effect on the discrimination ratio in the continuous-distractor task, since the interval between presentation and recall is much larger.

To sum up, there is strong evidence that short-term recency depends on the adoption of a retrieval strategy that involves recalling the last items first. The explicitness of this strategy is evident in its amenability to instruction. However, it remains less clear to what extent long-term recency depends on a similar explicit strategy. We know that output order per se is not critical in this case, but we also know that this can be understood in terms of the discrimination ratio. Interestingly, a number of authors have related the discrimination ratio to the phe- nomenological experience of mentally "looking back" over the time vista of past events (see, e.g., Crowder, 1976; Hitch, 1985); if valid, this would, of course, imply an explicit strategy.

\section{Discussion}

The primary-memory account of recency has a number of strengths. It is simple, it gives a good account of the effects of a filled delay and of the neuropsychological evidence, and, perhaps most importantly, it forms part of a coherent body of evidence related to an important theoretical issue, the need to distinguish between longand short-term memory. To what extent can our alternative view match these virtues?

There is no doubt that our model is more complex. However, it has considerably broader scope and makes a much more serious attempt to tackle the all-important issue of retrieval. Greater complexity is likely to be an inevitable feature of increased scope and greater attempted precision.

At first sight, the revised model appears to be less able to account for the neuropsychological data, since it appears to change the emphasis from a particular store to a mode of learning coupled with a strategy of retrieval. This discrepancy is, however, more apparent than real, since the revised model of recency is entirely compatible with the view that the immediate free recall of verbal material may depend on the registration of material in a phonological store that may be defective in patients suffering from short-term-memory deficit. Such a view would suggest that short-term-memory patients might well combine the absence of a recency effect in immediate free recall with clear evidence of long-term recency. Exactly this pattern was recently reported in the short-term-memory patient P.V., who showed no recency in immediate free recall of word lists but showed marked long-term recency in her capacity to recall anagram solutions (Vallar, Papagno, \& Baddeley, 1991).

In addition to its difficulties in accounting for some of the data, the primary-memory approach also has the drawback that it tends to raise the further question of whether long- and short-term recency are the same. According to our own interpretation, there is no simple answer to this; the two forms of recency are the same, in that they are assumed to involve the application of the same strategy to primed representations, but they are different in the sense that the representations will typically be within different memory and processing systems. Although posing research questions in an either-or mode can help stimulate controversy and encourage research, such an approach frequently has the longer term penalty of leading to a standoff. This in turn can result in disillusionment and the abandonment of the question, rather than the development of more complex interpretations that can account for all the data. It is, of course, important that such explanations lead to further testing, but provided they do so, such a synthesis can, in fact, be regarded as a positive step, rather than as reflecting the failure of early theorizing. 
Ideally, our link between recency and priming would allow the application of priming theory to the study of recency. Unfortunately, however, priming itself tends to have been regarded as a tool for investigating processing, rather than an area of intrinsic importance that itself demands explanation. It therefore seems appropriate to attempt to develop simultaneously theories of priming and theories of recency. One possible line of attack might be to attempt to link the duration of a given type of recency to the duration of the corresponding priming phenomenon, preferably using free recall and priming paradigms on exactly the same material. Another potential area of fruitful overlap concerns the question of what constitutes a category insofar as recency is concerned. Watkins and Peynircioglu (1983) demonstrated that it is possible to produce several recency effects in parallel, given that the categories of material are sufficiently distinct. This ought to have implications for priming and priming interference, with subsequent items from within a category disrupting priming to a greater extent than items from a distinct category.

A potentially important application of recency is to the task of switching attention from one task to another, a problem that is familiar to any busy administrator. Successful switching depends upon the capacity to reaccess the earlier topic rapidly and accurately, a capacity that one might speculate depends on some form of long-term recency effect. It is, indeed, plausible to assume that this capacity is an important component of executive function and of intelligence, a view that receives at least some support from the observation of Cohen and Sandberg (1977) that intelligence correlates more highly with the recency effect in immediate memory than with performance on earlier items.

Taking an even broader view, one might argue that recency performs the crucial function of helping the organism maintain orientation in time and space (Baddeley, 1988). Note that this is an argument for the usefulness of having privileged access to recent information and not a general justification for human beings having memory. Consider the simple situation of discussing an experiment with a colleague; halfway through the discussion the telephone rings, and you need to discuss the desirability of a repair to your car with the garage, before returning to the conversation with the question, "Now where were we?" One might reasonably argue that you would rely on the recency effect to tell you where you were. A rather more dramatic case occurs when one is traveling and wakes up in a strange bedroom from a deep sleep. Although the latter situation is not easy to investigate experimentally, it should in principle prove possible to set up laboratory simulations that investigate the time it takes to reorientate when switching from one state to another.

Finally, the willingness to consider recency in a broader context than that of primary memory is likely to offer novel ways of conceptualizing phenomena that have so far been largely neglected by students of memory. Consider, for example, the phenomenon of phantom limb pain in patients who have suffered an amputation. Melzack (1992) described the case of a Canadian lumberjack who suffered considerable pain from a sliver of wood lodged under his fingernail. While driving to the hospital, he was involved in an accident that resulted in the need to amputate the arm with the injured hand. He was left with a phantom limb and the continuing experience of the sliver under his nail. This is a particularly dramatic instance of a rather common phenomenon described by Katz and Melzack (1990), who surveyed the extensive evidence for such pain memories and carried out a prospective study to investigate them in more detail. They concluded that "when pain is experienced in a limb at or near the time of amputation there is a high probability that it will persist into the phantom limb and continue to cause the patient distress and suffering.... It appears that if there is a discontinuity or a pain-free interval between the experience of pain and amputation, the likelihood of that pain becoming incorporated into the phantom limb is reduced" (Katz \& Melzack, 1990, p. 331). They pointed out that it is now common practice to attempt to ensure that a pain-free interval precedes an amputation. Recency is, of course, not the only interpretation of this result, but it does suggest the possibility of an intriguing explanation that might offer a method of treatment, provided the patient's earlier experience of an intact and pain-free limb can in some sense be repeatedly recollected as part of the treatment, hence allowing the recency effect to be disrupted.

In conclusion, we suggest that the recency effect in immediate free recall should be regarded as simply one instantiation of a much broader phenomenon. This can best be conceptualized in terms of implicit learning, coupled with a particular mode of retrieval that may, but need not be, conscious and explicit. Hence, the recency effect can be viewed as reflecting the utilization of automatic activation by an active, multicomponent, working-memory system.

\section{REFERENCES}

Atuinson, R. C., \& Shiffrin, R. M. (1968). Human memory: A proposed system and its control processes. In K. W. Spence (Ed.), The psychology of learning and motivation: Advances in research and theory (Vol. 2, pp. 89-195). New York: Academic Press.

Baddeley, A. D. (1968). Prior recall of newly learned items and the recency effect in free recall. Canadian Journal of Psychology, 22, 157-163.

BADDELEY, A. D. (1970). Estimating the short-term component in free recall. British Journal of Psychology, 61, 13-15.

BADDELEY, A. D. (1981). The cognitive psychology of everyday life. British Journal of Psychology, 72, 257-269.

BADDELEY, A. D. (1982). Amnesia: A minimal model and an interpretation. In L. S. Cermak (Ed.), Human memory and amnesia (pp. 305336). Hillsdale, NJ: Erlbaum.

BADDELEY, A. D. (1986). Working memory. Oxford: Oxford University Press.

Baddeley, A. D. (1988). But what the hell is it for? In M. M. Gruneberg, P. E. Morris, \& R. N. Sykes (Eds.), Practical aspects of memory: Current research and issues: Vol. 1. Memory in everyday life (pp. 3-18). Chichester: Wiley.

BADDELEY, A. D. (1990). Human memory: Theory and practice. London: Erlbaum. 
BAdDeley, A. D. (1992). Working memory. Science, 255, 556-559. BAdDeley, A. D., \& Hitch, G. (1974). Working memory. In G. A Bower (Ed.), The psychology of leaming and motivation (Vol. 8 , pp. 47-89). New York: Academic Press.

BadDEley, A. D., \& Hitch, G. (1977). Recency re-examined. In S. Dornic (Ed.), Attention and performance (Vol. 6, pp. 647-667). Hillsdale, NJ: Erlbaum.

Baddeley, A. D., Warrington, E. K. (1970). Amnesia and the distinction between long- and short-term memory. Journal of Verbal Learning \& Verbal Behavior, 9, 176-189.

BAdDEley, A. D., \& WISON, B. A. (1988). Frontal amnesia and the dysexecutive syndrome. Brain \& Cognition, 7, 212-230.

BJoRK, R. A., \& WhITTEN, W. B. (1974). Recency-sensitive retrieval processes. Cognitive Psychology, 6, 173-189.

Brooks, D. N. (1975). Long- and short-term memory in head injured patients. Cortex, 11, 329-340.

Brown, N. R., Shevell, S. K., \& RiPS, L. J. (1986). Public memories and their personal context. In D. C. Rubin (Ed.), Autobiographical memory (pp. 137-158). Cambridge: Cambridge University Press.

Burgess, N., Shapiro, J. L., \& Moore, M. A. (1991). Neural network models of list learning. Network, 2, 399-422.

COHEN, R. L., \& SANDBERG, T. (1977). Relation between intelligence and short-term memory. Cognitive Psychology, 9, 534-554.

CraIK, F. I. M. (1968). Two components in free recall. Journal of Verbal Learning \& Verbal Behavior, 7, 996-1004.

CraIK, F. I. M. (1970). The fate of primary memory items in free recall. Journal of Verbal Learning \& Verbal Behavior, 9, 143-148.

Craik, F. I. M., \& LEVy, B. A. (1970). Semantic and acoustic information in primary memory. Journal of Experimental Psychology, 86, 77-82.

Craik, F. I. M., \& Lockhart, R. S. (1972). Levels of processing: A framework for memory research. Journal of Verbal Learning \& Ver bal Behavior, 11, 671-684.

Crowder, R. G. (1976). Principles of learning and memory. Hillsdale, NJ: Erlbaum

Dalezman, J. J. (1976). Effects of output order on immediate, delayed and final recall performance. Journal of Experimental Psychology. Human Learning \& Memory, 2, 597-608.

Darley, C. F., Tinklenberg, J. R., Roth, W. T., Holluster, L. E., \& Atxinson, R. C. (1973). Influence of marihuana on storage and retrieval processes in memory. Memory \& Cognition, 1, 196-200.

GLANZER, M. (1972). Storage mechanisms in recall. In G. H. Bower (Ed.), The psychology of learning and motivation: Advances in research and theory (Vol. 5, pp. 129-193). New York: Academic Press.

Glanzer, M., \& Cunitz, A. R. (1966). Two storage mechanisms in free recall. Joumal of Verbal Leaming \& Verbal Behavior, 5, 351-360.

Glanzer, M., \& KoppenaAl, L. (1977). The effect of encoding tasks on free recall: Stages and levels. Journal of Verbal Learning \& Verbal Behavior, 16, 21-28.

Glenberg, A. M., Bradley, M. M., Kraus, T. A., Renzaglia, G. J. (1983). Studies of the long-term recency effect: Support for a contextually guided retrieval hypothesis. Joumal of Experimental Psychology: Learning, Memory, \& Cognition, 9, 231-255.

Glenberg, A. M., Bradley, M. M., Stevenson, J. A., Kraus, T. A., Tkachuk, M. J., Gretz, A. L., Fish, J. H., \& Turpin, B. M. (1980). A two-process account of long-term serial position effects. Journal of Experimental Psychology: Human Learning \& Memory, 6, 355-369.

Graf, P., Squire, L. R., \& Mandler, G. (1984). The information that amnesic patients do not forget. Journal of Experimental Psychology: Leaming, Memory, \& Cognition, 10, 164-178.

GrFeNE, R. L. (1986a). A common basis for recency effects in immediate and delayed recall. Joumal of Experimental Psychology: Learning, Memory, \& Cognition, 12, 413-418.

Greene, R. L. (1986b). Sources of recency effects in free recall. Psychological Bulletin, 99, 221-228.

Hintzman, D. L. (1991). Contingency analyses, hypotheses and artifacts: A reply to Flexser and to Gardiner. Journal of Experimental Psychology: Learning, Memory, \& Cognition, 17, 341-345.
Hintzman, D. L., \& Hartry, A. L. (1990). Item effects in recognition and fragment completion: Contingency relations vary for different subsets of words. Joumal of Experimental Psychology: Leaming, Memory, \& Cognition, 16, 955-969.

HITCH, G. J. (1985). Short-term memory and information processing in humans and animals: Towards an integrated framework. In L.-G. Nilsson \& T. Archer (Eds.), Perspectives on learning and memory (pp. 119-136). London: Erlbaum.

Hitch, G. J., Rejman, M. H., \& Turner, N. C. (1980, July). A new perspective on the recency effect. Paper presented at the meeting of the Experimental Psychology Society, Cambridge, England

JACOBY, L. L., \& DALLAS, M. (1981). On the relationship between autobiographical memory and perceptual learning. Joumal of Experimental Psychology: General, 110, 306-340.

Katz, J., Melzack, R. (1990). Pain "memories" in phantom limbs: Review and clinical observations. Pain, 43, 319-336.

KirSner, K., \& SMITh, M. C. (1974). Modality effects in word identification. Memory \& Cognition, 2, 637-640.

McKenzie, W. A., \& Humphreys, M. S. (1991). Recency effects in direct and indirect memory tasks. Memory \& Cognition, 19, 321-331.

Melzack, R. (1992, April). Memory for pain. Paper presented at the meeting of the British Psychological Society, Scarborough, England.

Mewaldt, S. P., Hinrichs, J. V., \& Ghoneim, M. M. (1983). Diazepam and memory: Support for a duplex model of memory. Memory \& Cognition, 11, 557-564.

MonseLL, S. (1985). Repetition and the lexicon. In A. W. Ellis (Ed.), Progress in the psychology of language (pp. 147-196). London: Erlbaum.

Murdock, B. B., JR. (1963). Short-term retention of single paired associates. Journal of Experimental Psychology, 68, 184-189.

PARISI, G. (1986). A memory which forgets. Journal of Physics A: Mathematics \& General, 19, L617.

Parker, E. S., Schoenberg, R., Schwartz, B. L., \& Tulving, E. (1983). Memories on the rising and falling blood-alcohol curve. Bulletin of the Psychonomic Society, 21, 363.

PARKIN, A. J., \& STREete, S. (1988). Implicit and explicit memory in young children and adults. British Joumal of Psychology, 79, 361-369.

PinTo, A. DA C., BADDEley, A. D. (1991). Where did you park your car? Analysis of a naturalistic long-term recency effect. European Journal of Cognitive Psychology, 3, 297-313.

Rejman, M. H. (1979). Recency and primacy effects in short-term memory. Unpublished doctoral dissertation, University of Stirling, Stirling, Scotland

Richardson-Klavehn, A., \& Bjork, R. A. (1988). Measures of memory. Annual Review of Psychology, 39, 475-543.

Rundus, D. (1971). Analysis of rehearsal processes in free recall. Journal of Experimental Psychology, 89, 63-77.

SANDERS, A. F. (1975). The foreperiod effect revisited. Quanerly Journal of Experimental Psychology, 27, 591-598.

Seamon, J. G., \& Murray, P. (1976). Depth of processing in recall and recognition memory: Differential effects of stimulus meaningfulness and serial position. Journal of Experimental Psychology: Human Learning \& Memory, 2, 680-687.

Shallice, T., \& Warrington, E. K. (1970). Independent functioning of verbal memory stores: A neuropsychological study. Quarterly Journal of Experimental Psychology, 22, 261-273.

SQUIRE, L. (1982). The neuropsychology of human memory. Annual Review of Neuroscience, 5, 241-273.

ThURM, A. T., \& Glanzer, M. (1971). Free recall in children: Longterm store vs short-term store. Psychonomic Science, 23, 175-176.

Tulving, E. (1968). Theoretical issues in free recall. In T. R. Dixon \& D. L. Horton (Eds.), Verbal behavior and general behavior theory (pp. 2-36). Englewood Cliffs, NJ: Prentice-Hall.

Tulving, E., \& SChacter, D. L. (1990). Priming and human memory systems. Science, 247, 301-306.

Tulving, E., Schacter, D. L., \& Stark, H. E. (1982). Priming effects in word fragment completion are independent of recognition memory. Journal of Experimental Psychology: Learning, Memory, \& Cognition, 8, 336-342. 
Tzeng, O. J. L. (1973). Positive recency effects in delayed free re call. Journal of Verbal Learning \& Verbal Behavior, 12, 436-439.

Vallar, G., Papagno, C., \& Baddeley, A. D. (1991). Long-term recency effects and phonological short-term memory: A neuropsychological case study. Cortex, 27, 323-326.

Watkins, M. J., \& Peynircioglu, Z. F. (1983). Three recency effects at the same time. Journal of Verbal Leaming \& Verbal Behavior, 22, 375-384.

Waugh, N. C., \&orman, D. A. (1965). Primary memory. Psychological Review, 72, 89-104.
Whitten, W. B. (1978). Output interference and long-term serial position effects. Journal of Experimental Psychology: Human Leaming \& Memory, 4, 685-692.

Wilson, B. A., BAdDeley, A. D. (1988). Semantic and episodic memory in a post-meningitic amnesic patient. Brain \& Cognition, 8, $31-46$.

(Manuscript received May 15, 1992; revision accepted for publication August 26, 1992.) 